\title{
An acetone extract of Clausena anisata may be a potential control agent for flies encountered in cutaneous myiasis
}

\section{Authors:}

Lillian Mukandiwa ${ }^{1}$

Jacobus N. Eloff ${ }^{1}$

Donald R. Sibanda ${ }^{2}$

Vinny Naidoo ${ }^{1}$

\section{Affiliations:}

${ }^{1}$ Department of Paraclinical

Sciences, University of

Pretoria, South Africa

${ }^{2}$ Mpumalanga Veterinary Services, Siyabuswa, South Africa

Corresponding author: Lilian Mukandiwa, lilian.mukandiwa@up.ac.za

Dates:

Received: 28 Aug. 2015

Accepted: 10 Dec. 2015

Published: 24 May 2016

How to cite this article: Mukandiwa, L., Eloff, J.N., Sibanda, D.R. \& Naidoo, V., 2016, 'An acetone extract of Clausena anisata may be a potential control agent for

flies encountered in cutaneous myiasis', Onderstepoort Journal of Veterinary Research 83(1) a1045. http://dx.doi. org/10.4102/ojvr.v83i1.1045

\section{Copyright:}

(c) 2016. The Authors. Licensee: AOSIS. This work is licensed under the Creative Commons Attribution License.

\section{Read online:}

Scan this $Q R$ code with your smart phone or mobile device to read online.
Clausena anisata is a medicinal plant used traditionally to treat myiasis and as an insect repellent by various communities. We have previously demonstrated the effects of $C$. anisata extracts on blowfly feeding and development in our laboratory. The impact of $C$. anisata leaf extracts on populations of different fly species on farms in Mpumalanga, South Africa was investigated in this study under field conditions. Flies were exposed to liver baits treated with acetone leaf extracts of C. anisata $(150 \mathrm{mg} / \mathrm{mL})$. Fly numbers and composition on two farms, with and without $C$. anisata treated liver, were compared during a period of 12 weeks when fly populations were expected to be high. Observations were made on fly behaviour and development, adult sizes and numbers. The flies exposed to liver treated with the leaf extract of $C$. anisata had a decreased rate of development, prolonged larval period, smaller body sizes and more sluggish behaviour compared to those subjected to the control treatment. No significant differences were, however, found between the numbers and sizes of flies on the treated and on the control farm, which was most likely due to the limited nature of the baiting programme we followed. The effects of $C$. anisata extracts on blowfly behaviour and development observed in previous laboratory studies were confirmed in this field evaluation. Although the extracts did not have a significant effect on the overall population size in this experiment, we believe that the $C$. anisata leaf extract could be useful in integrated pest management based on its effect on larval development. In addition, species such as Lucilia cuprina and Chrysomya marginalis seemed to have been repelled by the C. anisata treated liver; as a result, further work should explore this aspect and how it can be used for the protection of animals.

\section{Introduction}

Myiasis, the infestation of live vertebrate animals with fly larvae, causes discomfort, loss in production, reproduction problems, blindness, lameness and even death in production animals (Sotiraki \& Hall 2012). Although myiasis has been recognised as a major disease from ancient times (Sherman, Hall \& Thomas 2000), in modern times the disease is still poorly controlled in the animal production industry of many countries. This leads to severe economic losses and animal deaths (Sotiraki \& Hall 2012; Wall 2012). Economic losses occur through abortions, decreased milk production, lower production, lower fertility, poor hide quality, muscle damage and even death from toxicity or secondary infections. There are 18 different genera of flies that may be involved in cutaneous myiasis. They belong to seven families, namely Calliphoridae, Sarcophagidae, Muscidae, Phoridae, Cuterebridae, Gasterophilidae and Oestridae (Hall 1991). Species of flies in the Calliphoridae, Sarcophagidae and Muscidae families are the main cause of cutaneous myiasis (Hall 1991).

Control of myiasis has largely relied on an integrated approach incorporating insecticides, husbandry practices (such as shearing, crutching, tail docking) (Phillips 2009), fly trapping (Urech et al. 2009; Wall 2012) and, in Australia, mulesing (Tellam \& Bowles 1997). Despite the integrated approach, a sustained reliance on the use of insecticides over many years has led to the inevitable development of blowfly populations resistant to insecticides (Heath \& Levot 2015). Other concerns with chemical compounds include the potential to cause human or animal toxicity. Residues left in wool released in effluent during scoring may also lead to environmental contamination. Consequently, there are increasing calls for the removal of certain blowfly control products from the international market, providing the impetus for non-insecticidal control methods (Bates 2012).

The fly population control method has been advocated as an alternative means of controlling myiasis (Knipling 1979). The advantage of this system is that the control measure decreases the 
number of adult flies in the environment without having to rely on the exposure of the animal and wool to high concentrations of ectoparasiticides. An example of an effective system is the LuciTrap system (Bioglobal Ltd, Australia), which has been effectively used to reduce fly densities and strike incidence in Australia (Ward \& Farrell 2003) and South Africa (Scholtz et al. 2000). The LuciTrap system consists of a translucent bucket made from tough ultraviolet-stabilised plastic and a removable lid with a flat surface, entrance cones that allow the sheep blowfly to enter but not leave the trap, and a bottle with the chemical attractant (LuciLure) (Levot 2009). The attractant consists of chemicals designed to mimic the odours of primary food sources of the sheep blowfly: fleece rot, animal carcasses, urine and faeces.

Clausena anisata (Willd.) Hook. f. ex. Benth., belonging to the Rutaceae family, is used for the treatment of myiasis in some communities in Zimbabwe (Chavunduka 1976) as a maggotexpelling agent. In Ethiopia, the leaves of this plant are used to repel houseflies (Karunamoorthi \& Husen 2012). It is also used as a repellent against various pests in different countries (Boeke et al. 2004; Mavundza et al. 2011; Ndomo et al. 2008). Our previous in vitro studies on the effect of the extracts of C. anisata on the blowfly larvae established that extracts of $C$. anisata deterred the second and third instar larvae of blowflies Lucilia cuprina and Chrysomya marginalis from feeding, resulting in lower pupae weights and smaller emerging adult flies (Mukandiwa, Eloff \& Naidoo 2012a; Mukandiwa et al. 2012b). Furthermore, a pyranocoumarin, seselin, isolated from the plant was identified as one of the compounds that deter blowfly larval feeding (Mukandiwa et al. 2013). In this study we explored the possibility of suppressing populations by attraction and inhibition of the life-cycle through the use of traps baited with ox-liver mixed with a plant insecticidal extract. We evaluated the efficacy of liver treated with $C$. anisata extracts against myiasis-causing flies in field trials on farms in the Mpumalanga province, South Africa.

\section{Materials and methods Study sites}

Fly populations were monitored at two farms in KwaMhlanga, $90 \mathrm{~km}$ north-east of Pretoria, South Africa. This area was selected based on the high prevalence of myiasis in the summer months, with in the order of 60 cases occurring per month (Area veterinarian, personal communication). Farm 1 served as a control baited with liver treated with the solvent only, whereas farm two was baited with liver treated with C. anisata. The farms were more than $10 \mathrm{~km}$ apart (treated farm: GPS coordinates $28^{\circ} 39^{\prime} 51^{\prime \prime} \mathrm{E}, 2^{\circ} 21^{\prime} 17^{\prime \prime}$ and control farm GPS coordinates $28^{\circ} 44^{\prime} 48^{\prime \prime} \mathrm{E}, 25^{\circ} 33^{\prime} 5^{\prime \prime}$ ) and were matched with regard to grazing environment; sheep breed, stocking density, flock management and climate. Both farms consisted of about 850 ha of predominantly natural pasture on which 100 sheep, 300 cattle and 80 goats are grazed. The migration of flies between the farms was eliminated as a factor because adult flies will not normally travel more than $3 \mathrm{~km}$ during their lifespan (Gleeson \& Heath 1997).

\section{Fly monitoring}

Fly abundance was monitored between December 2011 and April 2012 using Redtop flycatchers ${ }^{\circledR}$. Two traps were hung $100 \mathrm{~m}$ away from the sheep night-camps, $300 \mathrm{~m}$ apart, at a height of $1.2 \mathrm{~m}$ above the ground on trees as per the manufacturer's instructions. The initial trapping (which included three trappings on separate occasions) was done at the beginning of the study to establish the fly numbers on the farms. The counts from the three trappings were averaged and the average counts served as the starting fly numbers in the study areas; thereafter, fly trapping was done every 4 weeks. Each trapping lasted 48 hours and made use of rotten ox-liver as the bait. Ox-liver is a good attractant of flies encountered in myiasis (Blackwell et al. 1997; Parker \& Welch 1991). Following each trapping, all adult Diptera were counted, measured in size and identified according to the descriptions given by Howell, Walker and Nevill (1978).

\section{Collection and preparation of plant material}

The leaves of C. anisata (Willd.) Hook. f. ex. Benth. were collected in autumn from the National Botanical Garden, Pretoria, South Africa and dried at room temperature in a well-ventilated room. The plant species was identified by tree name tags and authenticated by the guide at the National Botanical Garden. The voucher specimen of the plant species, numbered PMDN317, is kept at the Medicinal Plant Collection Herbarium of the Department of Paraclinical Sciences, University of Pretoria, South Africa. Collection, drying and storage guidelines of the plant material followed were as outlined by McGaw and Eloff (2010). Dried and powdered leaves of C. anisata ( $437 \mathrm{~g}$ ) were extracted with acetone (5 L) at room temperature by continuous agitation on an orbital shaker (Labotec ${ }^{\circledR}$, model 202, South Africa) for 6 h. The mixture was filtered and the solvent removed under reduced pressure at low temperature $\left(40{ }^{\circ} \mathrm{C}-50{ }^{\circ} \mathrm{C}\right)$ with a rotary evaporator. The extraction process was repeated twice and extracts combined to give $37.9 \mathrm{~g}$ of dry acetone extract. The dried extract was reconstituted in acetone to make a $150 \mathrm{mg} / \mathrm{mL}$ stock of extract, which was used for the assays. The whole process was repeated when more extract was needed.

\section{Exposing flies to plant extract}

After the initial trapping, Farm 2 was exposed for 4 weeks to ox-liver treated with a $150 \mathrm{mg} / \mathrm{mL}$ acetone extract of C. anisata, placed in the Insectivorous Bird Feeders ${ }^{\circledast}$ (Stride Distributors CC, South Africa) (Figure 1). The concentration of extract was selected based on previous laboratory studies in which it was the most effective against blowfly larvae (Mukandiwa et al. 2012b). The feeder consists of a bait bucket with a perforated bottom inside a migration bucket, also with a perforated bottom, over a tray. Ideally, the feeding larvae migrate and drop into the feeding tray, where they can be eaten by birds. For this study the feeders were modified so that the bottom of the migration bucket was sealed to prevent the larvae from crawling out into the feeding tray of the feeder. The larvae fed on the bait in the smaller bucket until they crawled out, of their own accord, into the migration 


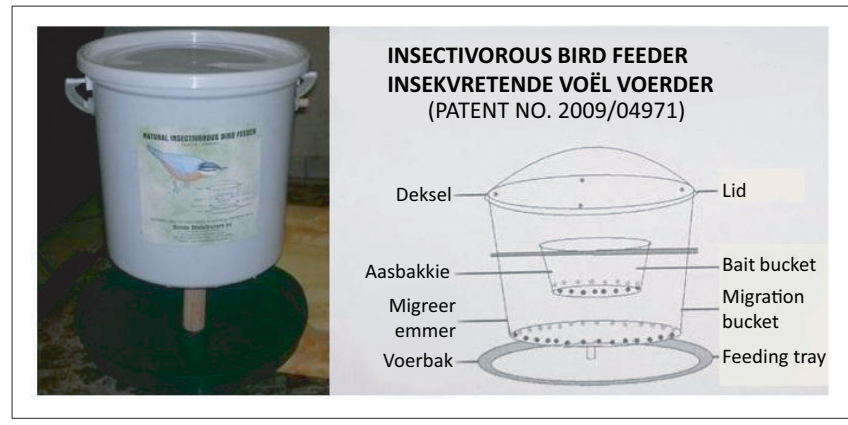

Source: Provided by Lillian Mukandiwa

FIGURE 1: The Insectivorous Bird Feeder".

bucket, which contained wood shavings to allow for growth and development into subsequent stages.

A mixture of $100 \mathrm{~g}$ of crushed ox-liver and $5 \mathrm{~mL}$ of plant extract $(150 \mathrm{mg} / \mathrm{mL})$ was placed in the bait bucket of the feeder $(n=10)$ around the sheep night-camps, $1.2 \mathrm{~m}$ above the ground. The feeders were left open for an hour in open space to enable the acetone to evaporate and then the lids were placed on top of the feeders to keep the rain out. Two holes were made on either side of the feeders to allow gravid female flies to enter and lay eggs on the liver extract mixture so that the emerging larvae would become exposed to the plant extract. The feeders were inspected every 2 days and the insecticide mixture replaced every 6 days. After the 4 weeks of baiting, trapping was done with the Redtop flycatcher $^{\circledR}$ for 48 hours for fly number quantification (as described above) prior to another 5 weeks of exposing flies to the baited ox-liver. Farm 1, which served as the control, was exposed to the same system as above with the exception that pure acetone was used in the bait (solvent control).

At each inspection of the feeders (every 2 days) we checked for the presence of fly eggs on the baits, and larval growth, movement and feeding activity were visually evaluated. For each group of pupae, 50 normal-looking pupae were taken to the laboratory for the emerging flies to be assessed.

\section{Statistical analysis}

The fly size data were evaluated by a non-parametric $t$-test for difference from the control group in SPSS 20 (IBM) as the counts were not normally distributed.

\section{Sensory evaluation of the extract}

A sensory evaluation of the extract was conducted to determine the acceptability of the extract for use. The participants in this evaluation included farmers, animal health personnel (veterinarians, veterinary nurses and animal health technicians) and researchers in ethnoveterinary studies. The respondents were blinded as to what the sample was and were asked to comment on the smell. The respondents were asked to rate the extract on a scale of: very bad, bad, neutral, nice and very nice. A total of 50 respondents were used. The reason for undertaking this analysis was to ensure that the extract would be aesthetically acceptable to people who would have to work with it.

\section{Results \\ Fly populations}

The flies caught in the Redtop flycatchers ${ }^{\circledR}$ were composed of blowflies Lucilia cuprina, Chrysomya albiceps and C. marginalis, the fleshfly, Sarcophaga haemorrhoidalis, and the housefly, Musca domestica. The changes in the populations of flies by species over time are presented in Table 1, whereas the changes in fly size are presented in Table 2. The sizes of $S$. haemorrhoidalis on the treated farm and the control farm were not significantly different $(p=0.362)$ at the beginning of the study. However, as the study progressed, the flies on the treated farm were significantly smaller $(p=0.02$ week 4 ; $p<0.00$, week $8 ; p=0.01$ week 12) than those on the control farm at any given point in time. There was no particular pattern of change in size with the other fly species (Table 2).

\section{Observations}

Flies were attracted to the baits of both farms and laid eggs. From the second day, according to inspections and by judging the stages of larvae observed in the baits after exposure, the eggs hatched within the mean standard period of 8-24 hours. However, by day 4 after hatching, all larvae, irrespective of species, that fed on the liver treated with $C$. anisata extract remained small, both in length and thickness, compared to

TABLE 2: Sizes (mean \pm s.d.) ( $\mathrm{mm}$ ) of the different fly species captured from the treated farm during a 12 -week period.

\begin{tabular}{|c|c|c|c|c|c|}
\hline \multirow[t]{2}{*}{ Fly species } & \multicolumn{5}{|c|}{ Time (weeks) } \\
\hline & Treatment & 0 & 4 & 8 & 12 \\
\hline \multirow{2}{*}{$\begin{array}{l}\text { Chrysomya } \\
\text { marginalis }\end{array}$} & Test & $12.2 \pm 0.5^{\mathrm{a}}$ & $12.5 \pm 0.4^{\mathrm{b}}$ & $11.7 \pm 0.5^{\mathrm{a}}$ & $10.7 \pm 0.4^{\mathrm{a}}$ \\
\hline & Control & $12.2 \pm 0.5^{\mathrm{a}}$ & $12.0 \pm 0.6^{\mathrm{a}}$ & $11.8 \pm 0.3^{\mathrm{a}}$ & $11.8 \pm 0.8^{b}$ \\
\hline \multirow{2}{*}{$\begin{array}{l}\text { Chrysomya } \\
\text { albiceps }\end{array}$} & Test & $12.0 \pm 0.3^{a}$ & $12.2 \pm 0.6^{\mathrm{a}}$ & $10.7 \pm 0.6^{a}$ & $11.8 \pm 0.5^{\mathrm{a}}$ \\
\hline & Control & $12.1 \pm 0.5^{a}$ & $12.2 \pm 0.8^{\mathrm{a}}$ & $11.1 \pm 0.4^{\mathrm{b}}$ & $11.3 \pm 0.6^{\mathrm{a}}$ \\
\hline \multirow[t]{2}{*}{ Lucilia cuprina } & Test & $10.6 \pm 0.4^{b}$ & $11.0 \pm 0.4^{b}$ & $9.0 \pm 0.8^{a}$ & $7.8 \pm 0.7^{\mathrm{a}}$ \\
\hline & Control & $10.0 \pm 0.5^{a}$ & $10.5 \pm 0.6^{a}$ & $9.0 \pm 0.6^{a}$ & $9.0 \pm 0.9^{b}$ \\
\hline \multirow{2}{*}{$\begin{array}{l}\text { Musca } \\
\text { domestica }\end{array}$} & Test & $8.0 \pm 0.3^{a}$ & $8.1 \pm 0.3^{a}$ & $7.8 \pm 0.4^{\mathrm{a}}$ & $7.8 \pm 0.5^{\mathrm{a}}$ \\
\hline & Control & $8.0 \pm 0.8^{a}$ & $8.0 \pm 0.0^{a}$ & $8.2 \pm 0.4^{b}$ & $8.0 \pm 0.5^{\mathrm{a}}$ \\
\hline \multirow{2}{*}{$\begin{array}{l}\text { Sarcophaga } \\
\text { haemorrhoidalis }\end{array}$} & Test & $14.8 \pm 0.3^{\mathrm{a}}$ & $15.0 \pm 0.0^{\mathrm{b}}$ & $13.0 \pm 0.6^{\mathrm{a}}$ & $13.1 \pm 0.5^{\mathrm{a}}$ \\
\hline & control & $14.6 \pm 0.5^{\mathrm{a}}$ & $14.8 \pm 0.3^{\mathrm{a}}$ & $15.0 \pm 0.2^{\mathrm{b}}$ & $14.5 \pm 0.6^{\mathrm{b}}$ \\
\hline \multicolumn{6}{|c|}{$\begin{array}{l}\mathrm{a}, \mathrm{b} \text {, For each fly type, at a given point in time, the test and control means with different } \\
\text { superscripts are significantly different }(p<0.05) \text {. }\end{array}$} \\
\hline lia cuprina & \multicolumn{3}{|c|}{ Sarcophaga haemorrhoidalis } & \multicolumn{2}{|c|}{ Musca domestica } \\
\hline Control & Treatec & Contr & & Treated & Control \\
\hline 198 & 79 & 51 & & 254 & 331 \\
\hline 314 & 87 & 35 & & 670 & 181 \\
\hline 192 & 13 & 18 & & 87 & 103 \\
\hline 71 & 5 & 8 & & 53 & 74 \\
\hline
\end{tabular}

TABLE 1: Number of flies over time on both the treated farm and the control farms.

\begin{tabular}{|c|c|c|c|c|c|c|c|c|c|c|}
\hline \multirow[t]{2}{*}{ Trapping } & \multicolumn{2}{|c|}{ Chrysomya albiceps } & \multicolumn{2}{|c|}{ Chrysomya marginalis } & \multicolumn{2}{|c|}{ Lucilia cuprina } & \multicolumn{2}{|c|}{ Sarcophaga haemorrhoidalis } & \multicolumn{2}{|c|}{ Musca domestica } \\
\hline & Treated & Control & Treated & Control & Treated & Control & Treated & Control & Treated & Control \\
\hline $13 / 01 / 2012$ & 133 & 120 & 167 & 180 & 260 & 198 & 79 & 51 & 254 & 331 \\
\hline $18 / 02 / 2012 \dagger$ & 1710 & 180 & 2730 & 220 & 1560 & 314 & 87 & 35 & 670 & 181 \\
\hline $23 / 03 / 2012$ & 102 & 100 & 133 & 110 & 101 & 192 & 13 & 18 & 87 & 103 \\
\hline 06/04/2012 & 38 & 17 & 12 & 33 & 50 & 71 & 5 & 8 & 53 & 74 \\
\hline
\end{tabular}

$\dagger$, Trapping was done 2 weeks after a cow died on the farm and was left in the open for 3 days on the treatment farm. 
the larvae that fed on liver treated with acetone only (Figure 2). By day 4, fly larvae on the control farm (Farm 1) were very active and began migrating into the migration bucket containing wood shavings (Figure 1); pupation was observed on day 6 . By day $14,90 \%$ of the pupae had hatched. However, on the treated Farm 2, the larvae were less active than the control group and more than $95 \%$ of them failed to crawl into the migration bucket, pupating instead in the bait bucket.

The larval stage was also prolonged for all the fly species that were on the treated liver, with the total period from hatching to pupation lasting 17-21 days. The larval stages lasted 4-6 days in the life-cycles of all the fly species encountered in this study, under the weather conditions in which this study was undertaken. A relatively small number, approximately $20 \%$, of dead larvae were observed on the liver treated with the $C$. anisata extract. However, the dead larvae could not be counted as this could have disturbed the rest of the larvae.

The majority of the emerging pupae (90\%) from the treated groups appeared normal, and $75 \%$ of these pupae hatched after 2 weeks of pupation (days 35-42). In the control group, all the pupae hatched within 6-7 days of pupation (days 13-14). Abnormal pupae were observed on the treated farm (Figure 3).

Of the $200 \pm 5$ pupae collected for laboratory assessment, $75 \%$ from the treated farm eclosed, yielding only the fleshfly,

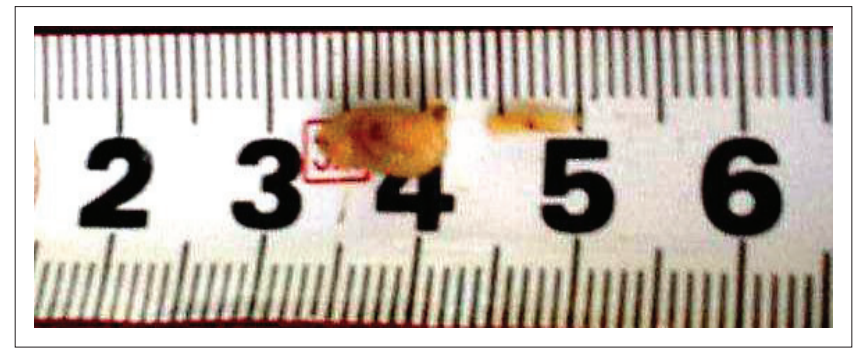

Source: Provided by Lillian Mukandiwa

FIGURE 2: Illustration of the different size of 4-day-old larvae from the contro farm and the treated farm, from left to right.

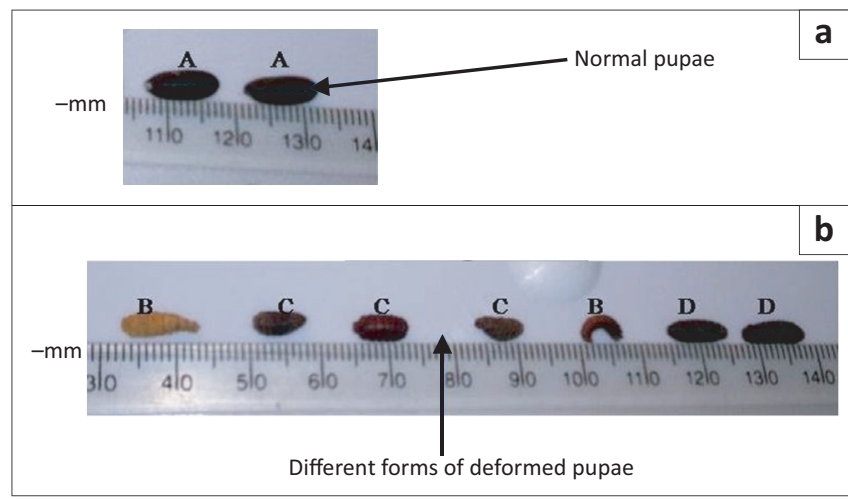

Source: Provided by Lillian Mukandiwa

A, Normal pupae; B, Larviform (an intermediate between larvae and pupae); C, Mal-shaped pupae; D, Segmented pupae.

FIGURE 3: ( $a, b)$ Different forms of abnormal pupae emerging from the test farm $(B-D)$ compared to the normal pupae from the control farm (A).
S. haemorrhoidalis; the rest of the pupae did not eclose. All the pupae from the control farm hatched, giving a mixed population of flies consisting of blowflies (77\%), fleshflies (4\%) and houseflies (19\%). When the pupae from Farm 2 that failed to hatch were cracked open, by holding the pupae between the forefinger and thumb and gently applying pressure, half-developed flies were found that had all their appendages (head, abdomen and legs) except the wings (Figure 4).

To ascertain whether the absence of blowflies in the samples taken for laboratory assessment from the treated farm was due to the extract and not an artefact, untreated liver was hung around the sheep camps. The eggs laid were taken to the lab to develop into subsequent stages and $93 \%$ of the emerging flies were blowflies, Lucilia and Chrysomya spp.

\section{Sensory evaluation of extract}

The majority of the respondents (64\%) found the smell of the extract to be neutral (neither bad nor nice), with none of the respondents rating it very bad or very nice (Figure 5).

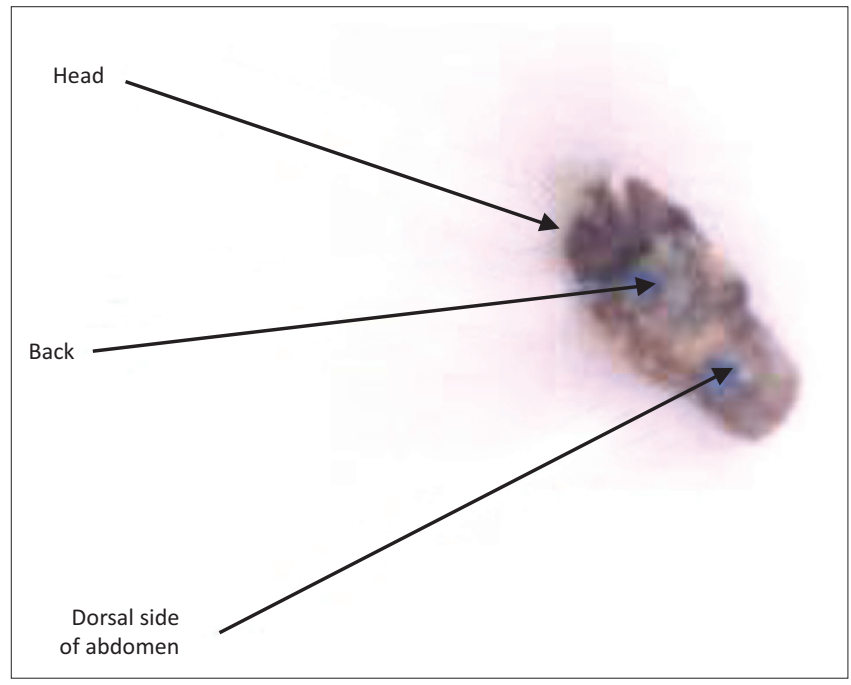

Source: Provided by Lillian Mukandiwa

FIGURE 4: Half-developed flies from the pupae that failed to hatch naturally.

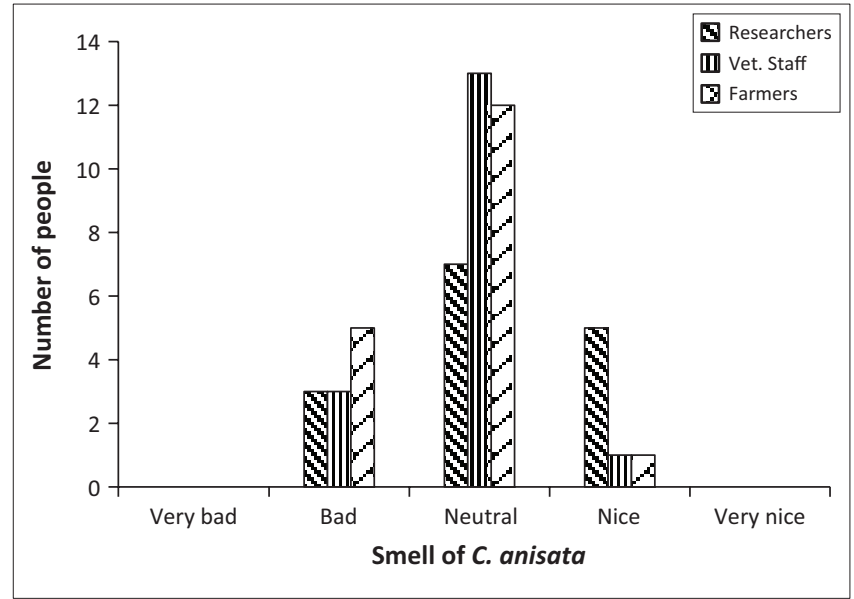

Source: Provided by Lillian Mukandiwa

FIGURE 5: Summary of results on the sensory evaluation of the Clausena anisata extract. 


\section{Discussion}

One of the major findings of this study was the prolonged time of 17-21 days taken for the baited larvae to pupate in comparison to 4-6 days for the control larvae. This is an important result, as the prolongation of the life-cycle increases the chances of death in the environment. Ultimately this would reduce the total population, as the total number of life-cycles in one breeding season would be reduced.

The data from the monitoring trappings indicated the presence of a mixed population of Lucilia, Chrysomya, Sarcophaga and Musca species, but surprisingly only S. haemorrhoidalis emerged from the pupae collected from the treated farm. When untreated liver was hung around the sheep camps on the treated farm, the flies that emerged from the collected eggs were largely Lucilia cuprina, Chrysomya albiceps and C. marginalis. This suggests that either the Lucilia, Chrysomya and Musca species were more susceptible to the extract and did not survive to the adult stage, or they avoided the baits. The last option is most plausible, as the fly numbers and the size of the adult Lucilia, Chrysomya and Muscidae species did not significantly change as the study progressed, as was observed with $S$. haemorrhoidalis. In previous studies under laboratory conditions the Lucilia and Chrysomya species laid eggs on the treated baits (Mukandiwa et al. $2012 b)$. The contradictory results may be because the flies had no other options as they were kept in a cage with only this site for oviposition. In a different setup where there are alternatives, the flies will avoid the C. anisata treated baits, suggesting the possibility that this extract may have potential benefits as a repellent that can be used on the animal as a wound dressing to keep blowflies away. This would also validate the traditional use in which the leaves are packed onto wounds to expel maggots (Chavunduka 1976) and probably to keep the flies away. We have previously established the safety of $C$. anisata leaf extracts in a cytotoxicity study (Mukandiwa et al. 2012b). However, further studies will need to be conducted in vivo to establish the efficacy and safety of the C. anisata extract as a wound dressing.

If the argument above holds that the blowflies were repelled, it does not agree with earlier studies that evaluated the extract against the blowflies L. cuprina and C. marginalis (Mukandiwa et al. 2012a, 2012b) under laboratory conditions. However, some conclusions can be drawn. The extract had a feeding deterrence effect on different fly species as the larvae on treated meat were smaller than on the control group both in the laboratory and in current studies. The extract also prolonged the pre-puparium stage in different fly species. Therefore the effects of the acetone extract of $C$. anisata with regard to reduced larval sizes and the prolonged prepuparium stage, although for different fly species, were the same under both laboratory and field conditions.

At present, the mechanism of action of the extracts is unknown. However, based on the effects seen, 2 explanations are plausible, that is, the presence of feeding deterrents or the presence of juvenile hormone mimics. Plant-derived compounds have been shown to affect the feeding and diet-selection behaviour of the larvae of blowflies (Green, Simmonds \& Blaney 2002; Mukandiwa et al. 2012a, 2012b). Some are toxic whereas others act as feeding deterrents; for example, Phormia regina larvae avoided diets containing $10 \mathrm{ppm}$ and $100 \mathrm{ppm}$ azadirachtin and $10 \mathrm{ppm}$ pyrethrum extract (Green et al. 2004). The alkaloids arecoline, caffeine, quinine and nicotine, among others, reduce food consumption in blowfly larvae, resulting in reduced weights of the larvae (Green et al. 2002). Clausena anisata contains various alkaloids: atanisatin, clausanitin clausenol, clausenine girinimbine, heptaphylline, 3-methylcarbazole, 1-methyl-3,4-dimethoxy2-quinolone, 3-formyl-1-hydroxycarbazole, murrayamine-A and ekeberginine furanoclausamine $\mathrm{A}$ and $\mathrm{B}$, clausamine A-H, mukonal, glycosinine, mukonidine and clausine $\mathrm{F}$ clausanitine and mupamine (Ojewole 2002). Whereas the effects of each alkaloid listed here have not been established in laboratory studies, this class of compounds is known to act as feeding deterrents to insects and herbivores (War et al. 2012) In addition, C. anisata contains the coumarins imperatorin and xanthoxyletin, which have an anti-feeding effect on insects (Gebreyesus \& Chapya 1983). We also isolated the pyranocoumarin, seselin $(2 \mathrm{H}, 8 \mathrm{H}-\mathrm{Benzo}[1,2-\mathrm{b}: 3$, 4-b']dipyran-2-one,8,8-dimethyl), from the $C$. anisata extract as the feeding deterrent (anorexogenic agent) against blowfly larvae (Mukandiwa et al. 2013).

The other plausible and more likely reason for the prolonged life-cycle, 21 days in comparison to the 4-6 days of the control, may be more physiologically based, as plants are known to produce insect juvenile hormones (Bede \& Tobe 2000). The major function of juvenile hormone is the maintenance of the larval status or the so-called juvenilising effect (Dhadialla, Retnakaran \& Smagghe 2005). The plant extract had effects similar to other insect growth regulators (IGRs), which include reduced development and a prolonged larval period, a smaller body size at a given time compared to the control, and sluggish behaviour, delayed pupation and a reduced eclosion rate of pupae and adults. The IGRs include the juvenile hormone analogues, ecdysone agonists and inhibitors and chitin synthesis inhibitors. Ultimately, IGRs control insect populations (Mondal \& Parween 2000), albeit over a longer period of time. Previous studies showed that IGRs caused a decline in populations of the German cockroach (Blattella germanica L.) in 3-4 months after the start of baiting or spraying treatment, with complete eradication after 12 months (Mosson et al. 1995). Our study period may therefore have been too short for the extract to begin to have effects on the total fly populations. This is supported by the lack of a clear pattern in the fly populations over our study.

The other aim of this study was to ascertain the feasibility of using this plant extract in the field. The two major concerns were the possible unpleasant smell of the extract and chemical instability in the environment. For the first characteristic, the smell of the plant extract was scored by different individuals as being acceptable. This was an important finding, because the leaves of $C$. anisata, from which the extract was derived, are known to be densely dotted with glands and have a 
strong scent when crushed. The scent is highly unpleasant, characteristic of horse urine as suggested by the common Afrikaans name, Perdepis (horse urine) (Schmidt, Lotter \& McCleland 2002). However, for this study the acetone leaf extract was rated by $64 \%$ as having a neutral smell, which implies either that the compounds that give $C$. anisata leaves their characteristic smell are not present in a high enough concentration in the acetone extract or that they were masked by other compounds. Regarding our concerns about its stability, the extract proved to remain constantly effective despite being changed every 5 days. In the laboratory studies the larvae were exposed to the extract for 48 hours only.

Successful fly population control requires an integrated approach that would include removal of other food sources in the environment. This was clearly evident in this study, as the unscheduled death of a cow led to a massive increase in the number of flies trapped 2 weeks later, despite baits still having their desired effect.

\section{Conclusion}

The effect on the larval growth and pupal shape make this extract a candidate for further evaluation in the search for new fly-control products. A longer study period is necessary to establish conclusively the effect of the extract on the total population of flies in the environment. Furthermore, the extract seemed to repel the blowflies from the baits, suggesting that it may be used as a topical product on animals to repel blowflies.

\section{Acknowledgements Competing interests}

The authors declare that they have no financial or personal relationships which may have inappropriately influenced them in writing this article.

\section{Authors' contributions}

L.M. designed and conducted the experiments and drafted the manuscript. J.N.E. was involved in originating the research and writing up the manuscript. D.R.S. conducted the experiments and was involved in data collection and in writing up the manuscript. V.N. participated in the design of the study, data analysis and interpretation of the results. All the authors read and approved the final manuscript.

\section{References}

Bates, P.G., 2012, External parasites of small ruminants: A practical guide to their prevention, CAB International, Wallingford.

Bede, J.C. \& Tobe, S.S., 2000, 'Insect juvenile hormones in plants', Studies in Natural Products Chemistry 22, 369-418. http://dx.doi.org/10.1016/S15725995(00)80031-9

Blackwell, G.L., Potter, M.A., Cottam, Y.H. \& Blair, H.T., 1997, 'Susceptibility of Romney and Perendale sheep to flystrike by the Australian green fly, Lucilia cuprina (Wied.), and fly attractant trials', Proceedings of the New Zealand Society of Animal Production 57, 37-40.

Boeke, S.J., Baumgart, I.R., Van Loon, J.J.A., Van Huis, A., Dicke, L.M. \& Kossou, D.K., 2004, 'Toxicity and repellence of African plants traditionally used for the protection of stored cowpea against Callosobruchus maculatus', Journal of Stored Product Research 40, 423-438. http://dx.doi.org/10.1016/S0022-474X(03)00046-8
Chavunduka, D.M., 1976, 'Plants regarded by Africans as being of medicinal value to animals', Rhodesian Veterinary Journal 7, 6-12.

Dhadialla, T.S., Retnakaran, A. \& Smagghe, G., 2005, 'Insect growth and development disrupting insecticides', in L.I. Gilbert, I. Kostas \& S. Gill (eds.), Comprehensive insect molecular science, pp. 55-116, Pergamon Press, New York.

Gebreyesus, T. \& Chapya, A., 1983, 'Antifeedants from Clausena anisata (Willd.) Hook F. ex. Benth. (Rutaceae)', in D.L. Whitehead \& W.S. Bower (eds.), Natural products for innovative pest management, pp. 237-241, Pergamon Press, Oxford.

Gleeson, D.M. \& Heath, A.C.G., 1997, 'The population biology of the Australian sheep blowfly, Lucilia cuprina, in New Zealand', New Zealand Journal of Agricultura Research 40, 529-535. http://dx.doi.org/10.1080/00288233.1997.9513275

Green, P.W.C., Simmonds, M.S.J. \& Blaney, W.M., 2002, 'Toxicity and behavioural effects of alkaloids on larvae of the black blowfly, Phormia regina', Medical and Veterinary Entomology 16, 157-160. http://dx.doi.org/10.1046/j.1365-2915. 2002.00358.x

Green, P.W.C., Simmonds, M.S.J., Blaney, W.M. \& Khambay, B.P.S., 2004, 'Effects of plant-derived compounds on larvae of a blowfly species that causes secondary myiases: Laboratory studies', Phytotherapy Research 18, 538-541. http://dx.doi. org/10.1002/ptr.1480

Hall, M.J.R., 1991, 'Screwworm flies as agents of wound myiasis', in R.D.S. Branckaert (ed.), New world screwworm: Response to an emergency, World Animal Review, pp. 8-17, Food and Agriculture Organization of the United Nations, Rome.

Heath, A.C.G. \& Levot, G.W., 2015, 'Parasiticide resistance in flies, lice and ticks in New Zealand and Australia: Mechanisms, prevalence and prevention', New Zealand Veterinary Journal 22, 1-12. http://dx.doi.org/10.1080/00480169.2014.960500

Howell, C.J., Walker, J.B. \& Nevill, E.M., 1978, Ticks, mites and insects infesting domestic animals in South Africa, Science Bulletin 393, Department of Agricultural Technical Services South Africa, Government Printer, Pretoria.

Karunamoorthi, K. \& Husen, E., 2012, 'Knowledge and self-reported practice of the local inhabitants on traditional insect repellent plants in Western Hararghe zone, Ethiopia', Journal of Ethnopharmacology 141, 212-219. http://dx.doi. org/10.1016/j.jep.2012.02.022

Knipling, E.F., 1979, The basic principles of insect population suppression and management, United States Department of Agriculture, Washington, DC.

Levot, G., 2009, Trapping blowflies, Primefact 842, Industry \& Investment New South Wales, Sydney.

Mavundza, E.J., Maharaj, R., Finnie, J.F. \& Van Staden, J., 2011, 'An ethnobotanica survey of mosquito repellent plants in uMkhanyakude district, KwaZulu-Natal Province, South Africa', Journal of Ethnopharmacology 137, 1516-1520. http:// dx.doi.org/10.1016/j.jep.2011.08.040

McGaw, L.J. \& Eloff, J.N., 2010, 'Methods for evaluating efficacy of ethnoveterinary medicinal plants', in D.R. Katerere \& D. Luseba (eds.), Ethnoveterinary Botanical Medicine: Herbal Medicines for Animal Health, pp. 1-24, CRC Press, London.

Mondal, K.A.M.S.H. \& Parween, S., 2000, 'Insect growth regulators and their potential in the management of stored-product insect pests', Integrated Pest Management Review 5, 255-295. http://dx.doi.org/0.1023/A:1012901832162

Mosson, H.J., Short, J.E., Schenker, R. \& Edwards, J.P., 1995, 'The effects of the insect growth regulator lufenuron on oriental cockroach, Blatta orientalis, and German
cockroach, Blattella germanica, populations in simulated domestic environments', cockroach, Blattella germanica, populations in simulated domestic environ
Pesticide Science 45, 237-246. http://dx.doi.org/10.1002/ps.2780450307

Mukandiwa, L., Ahmed, A., Eloff, J.N. \& Naidoo, V., 2013, 'Isolation of seselin from Clausena anisata leaves and its effects on the growth and development of blowfly Clausena anisata leaves and its effects on the growth and development of blowfly larvae', Journal of Et
jep.2013.09.037

Mukandiwa, L., Eloff, J.N., McGaw, L.J. \& Naidoo, V., 2012a, 'Extracts of four plant species used traditionally to treat myiasis influence pupation rate, pupal mass and adult blowfly emergence of Lucilia cuprina and Chrysomya marginalis and adult blowfly emergence of Lucilia cuprina and Chrysomya marginalis
(Diptera: Calliphoridae)', Journal of Ethnopharmacology 143, 812-818. http:// (Diptera: Calliphoridae)', Journal of Ethr
dx.doi.org/10.1016/j.jep.2012.07.041

Mukandiwa, L., Eloff, J.N. \& Naidoo, V., 2012b, 'Evaluation of plant species used traditionally to treat myiasis for activity on the survival and development of Lucilia cuprina and Chrysomya marginalis (Diptera: Calliphoridae)', Veterinary Lucilia cuprina and Chrysomya marginalis (Diptera: Calliphoridae)', Veterinar
Parasitology 190, 566-572. http://dx.doi.org/10.1016/j.vetpar.2012.06.027

Ndomo, A.F., Ngamo, L.T., Tapondjou, L.A., Tchouanguep, F.M. \& Hance, T., 2008, Insecticidal effects of the powdery formulation based on clay and essential oil from the leaves of Clausena anisata (Willd.) J.D. Hook ex. Benth. (Rutaceae) against Acanthoscelides obtectus (Say) (Coleoptera: Bruchidae)', Journal of against Acanthoscelides obtectus (Say) (Coleoptera: Bruchidae)', Journal
Pesticide Science 81, 227-234. http://dx.doi.org/10.1007/s10340-008-0211-3

Ojewole, J.A.O., 2002, 'Hypoglycaemic effect of Clausena anisata (Willd.) Hook methanolic root extract in rats', Journal of Ethnopharmacology 81, 231-237. http://dx.doi.org/10.1016/S0378-8741(02)00085-5

Parker, F.D. \& Welch, J.B., 1991, 'Field comparisons of attractants for the screw worm fly (Diptera: Calliphoridae) in a tropical dry forest in Costa Rica', Journal of Economic Entomology 84, 189-1195. http://dx.doi.org/10.1093/jee/84.4.1189

Phillips, C.J.C., 2009, 'A review of mulesing and other methods to control flystrike (cutaneous myiasis) in sheep', Animal Welfare 18, 113-121.

Schmidt, E., Lotter, M. \& McCleland, W., 2002, Trees and Shrubs of Mpumalanga and Kruger National Park, Jacana, Johannesburg.

Scholtz, A.J., Cloete, S.W.P., Laubscher, J.M. \& De Beer, E.F., 2000, 'A preliminary evaluation of a sheep blowfly trap in the Western Cape', Journal of the South African Veterinary Association 71, 148-152. http://dx.doi.org/10.4102/jsava.v71i3.704

Sherman, R.A., Hall, M.J.R. \& Thomas, S., 2000, 'Medicinal maggots: An ancient remedy for some contemporary afflictions', Annual Review of Entomology 45, 55-81. http://dx.doi.org/10.1146/annurev.ento.45.1.55 
Sotiraki, S. \& Hall, M.J.R., 2012, 'A review of comparative aspects of myiasis in goats and sheep in Europe', Small Ruminant Research 103, 75-83. http://dx.doi. org/10.1016/j.smallrumres.2011.10.021

Tellam, R.L. \& Bowles, V.M., 1997, 'Control of blowfly strike in sheep: Current strategies and future prospects', International Journal of Parasitology 27, 261-273. http:// dx.doi.org/10.1016/S0020-7519(96)00174-9

Urech, R., Green, P.E., Rice, M.J., Brown, G.W., Webb, P., Jordan, D. et al., 2009 'Suppression of populations of Australian sheep blowfly, Lucilia cuprina (Wiedemann) (Diptera: Calliphoridae), with a novel blowfly trap', Australian Journa of Entomology 48, 182-188. http://dx.doi.org/10.1111/j.1440-6055.2009.00701.x
Wall, R., 2012, 'Ovine cutaneous myiasis: Effects on production and control', Veterinary Parasitology 189, 44-51. http://dx.doi.org/10.1016/j.vetpar.2012. 03.031

War, A.R., Paulraj, M.G., Ahmad, T., Buhroo, A.A., Hussain, B., Ignacimuthu, S. et al., 2012, 'Mechanisms of plant defense against insect herbivores', Plant Signaling and Behavior 7, 1306-1320. http://dx.doi.org/10.4161/psb.21663

Ward, M.P. \& Farrell, R., 2003, 'Sheep blowfly strike reduction using a synthetic lure system', Preventive Veterinary Medicine 59, 21-26. http://dx.doi.org/10.1016/ S0167-5877(03)00059-X 